\title{
Lesões esportivas durante lutas no boxe amador
}

\author{
Sports injuries during fights in amateur boxing
}

Carlos Augusto Beltrani Filho', Ismael Vivácqua Neto², Marcelo Schmidt Navarro', Edison Noboru Fujiki', Vitor Engrácia Valenti', Luiz Carlos de Abreu', Carlo Milani'

\section{Resumo}

Introdução: As patologias que acometem os atletas do boxe são, na maioria, traumáticas e acometem principalmente as extremidades superiores e a face. A supervisão médica aos atletas aprimorou o aprendizado sobre as lesões específicas do boxe. A partir dos conhecimentos adquiridos, foram estabelecidas medidas profiláticas para preservar a saúde do atleta e evitar afastamentos do esporte. Objetivo: Descrever as lesões ocorridas durante as lutas de boxe amador masculino sob supervisão médica, a fim de promover um melhor entendimento dessas patologias. Método: Entre 2000 e 2009, por meio da aplicação de um protocolo padronizado, descrevemos as lesões nos atletas masculinos do boxe amador, durante as lutas realizadas pela Confederação Brasileira de Boxe, Federação Paulista de Boxe, Confederação Pan-Americana de Boxe e Associação Internacional de Boxe. Resultados: No total, foram realizadas 1.446 lutas, com 291 lesões, como nocautes (48,8\%), sangramentos nasais (23,5\%), lesões musculoesqueléticas (15,5\%), ferimentos cortocontusos $(8,6 \%)$ e hematoma palpebral $(3,6 \%)$. Das lesões musculoesqueléticas, $5,8 \%$ foram lesões ligamentares nas mãos e punhos, 3,7\% fraturas nas mãos e punhos e $2 \%$ luxações glenoumerais. Conclusões: As principais lesões durante as lutas da equipe nacional de boxe foram os nocautes, seguidas de sangramentos nasais, lesões musculoesqueléticas e ferimentos cortocontusos. As lesões mais comuns foram na face e nas mãos.

Palavras-chave: Traumatismos em atletas; boxe; medicina esportiva.

\begin{abstract}
Introduction: Most of the pathologies that attack boxing athletes are traumatic and occur in the superior extremities and in the face. The medical supervision to the athletes improved the learning about specific lesions of boxing. Starting from the acquired knowledge, prophylactic measures were instituted in order to preserve athlete's health and to avoid removals from the sport. Objective: To describe the injuries occurred during male amateur boxing under medical supervision in order to promote a better understanding of these pathologies. Methods: Between 2000 and 2009 , by applying a standardized protocol, we described the injuries in male athletes of amateur boxing during the struggles waged by the Brazilian Boxing Confederation, São Paulo Boxing Federation, Pan-American Boxing Confederation and International Boxing Association. Results: The total of 1.446 fights were accomplished, with 291 lesions as knockouts (48.8\%), nasal bleeding (23.5\%), musculoskeletal lesions (15.5\%), open wounds (8.6\%) and palpebral bruise (3.6\%). Among the musculoskeletal lesions, $5.8 \%$ were ligament lesions in hands and wrists, $3.7 \%$ were fractures in hands and wrists, and $2 \%$ were glenohumeral dislocation. Conclusions: The main lesions during the fights of the Brazilian boxing team were knockouts, nasal bleeding, musculoskeletal lesions and open wounds. The most common lesions occured in the face and in the hands.
\end{abstract}

Keywords: Athletic injuries; boxing; sports medicine.

Recebido: 19/5/2009

Revisado: $30 / 10 / 2009$

Aprovado: 28/12/2009

\footnotetext{
Trabalho realizado na Faculdade de Medicina do ABC (FMABC), Santo André (SP), Brasil

Grupo de Traumatologia Esportiva da Disciplina de Ortopedia e Traumatologia da Faculdade de Medicina do ABC (FMABC), Santo André (SP), Brasi

2 Confederação Brasileira de Boxe, São Paulo (SP), Brasil

Endereço para correspondência: Carlos Augusto Beltrani Filho - Hospital Estadual Mário Covas - Rua Henrique Calderazzo, $321,5^{\circ}$ andar - Paraíso -

CEP 09190-615 - Tel.: (11) 2829-5000 - Santo André (SP) - E-mail: beltranifilho@hotmail.com
} 


\section{Introdução}

As lesões podem ser consideradas como o principal fator de afastamento de atletas da sua modalidade esportiva. Esse afastamento é prejudicial, pois influencia diretamente no seu desempenho físico e técnico, além dos possíveis prejuízos psicológicos, já que a recuperação pode ser demorada, exigindo deles paciência e cautela para retornar à atividade: e consequentemente, a equipe também é prejudicada.

As lesões, muitas vezes, ocorrem em momentos importantes de suas carreiras, afastando-os de competições, retirando-os de seleções e, em alguns casos, provocando o abandono precoce da carreira.

Cada esporte tem suas características próprias de espaço, tempo, dinâmica e exigência física, o que pode determinar o tipo de lesão mais frequente em cada um deles. No caso do boxe, o contato físico é predominante.

O boxe é um dos mais antigos esportes da humanidade e, apesar da percepção de brutalidade associada ao desporto, a minoria das lesões que acometem os pugilistas são graves ou incapacitantes ${ }^{1}$.

Tabela I - Lesões nas lutas do boxe amador

\begin{tabular}{lccc}
\hline Lesões & Número & $\begin{array}{c}\text { Porcentagem } \\
(\%)\end{array}$ & $\begin{array}{c}\text { Porcentagem } \\
\text { das lutas (\%) }\end{array}$ \\
\hline Nocautes & 142 & 48,8 & 9,8 \\
Sangramentos nasais & 68 & 23,5 & 4,7 \\
Lesões musculoesqueléticas & 45 & 15,5 & 3,1 \\
Ferimentos cortocontusos & 26 & 8,6 & 1,8 \\
Hematoma palpebral & 10 & 3,6 & 0,7 \\
Total & 291 & 100 & 20,1 \\
\hline
\end{tabular}

Tabela II - Tipos de lesões musculoesqueléticas nos atletas do boxe amador

\begin{tabular}{lcc}
\hline Lesões musculoesqueléticas & Número & Porcentagem (\%) \\
\hline Lesão ligamentar da mão e punho & 17 & 5,8 \\
\hline Fratura da mão e punho & 11 & 3,7 \\
Luxação glenoumeral & 6 & 2 \\
\hline Fratura nasal & 4 & 1,4 \\
Lesão do ligamento cruzado do joelho & 3 & 1 \\
\hline Fratura do zigomático & 1 & 0,3 \\
Fratura da costela & 1 & 0,3 \\
Fratura do antebraço & 1 & 0,3 \\
Fratura do tornozelo & 1 & 0,3 \\
Total & 45 & 15,5 \\
\hline
\end{tabular}

Tabela III - Locais dos ferimentos cortocontusos nos atletas do boxe amador

\begin{tabular}{lcc}
\hline Locais dos ferimentos & Número & Porcentagem (\%) \\
\hline Supraorbital & 13 & 4,1 \\
Intrabucal & 7 & 2,4 \\
Palpebral & 2 & 0,6 \\
Lábio inferior & 2 & 0,6 \\
Nasal & 1 & 0,3 \\
Mento & 1 & 0,3 \\
Total & 26 & 8,6 \\
\hline
\end{tabular}

A maioria das patologias que acometem os atletas do boxe é de origem traumática, principalmente nas extremidades superiores, cabeça e face. Algumas vezes, a carreira do atleta pode ser comprometida devido à gravidade dessas lesões².

A supervisão médica foi incorporada pelas principais associações mundiais de boxe a partir da década de $50^{3}$, com intuito de proporcionar melhorias no atendimento aos atletas e adoção de medidas profiláticas ${ }^{4}$. Tais medidas foram adotadas, como o uso de protetores de cabeça, mãos e punhos, a fim de minimizar os índices de lesões e de afastamentos do esporte $\mathrm{e}^{5}$.

Ademais, o boxe é um esporte perigoso. Contrariamente à maioria dos outros esportes, ele tem por principal objetivo golpear o adversário. O boxe pode provocar a morte e causar lesões cerebrais crônicas. Esta é a razão pela qual a Associação Médica Mundial recomenda que a prática do boxe seja proibida.

Portanto, o objetivo deste trabalho foi descrever as lesões durante as lutas de boxe em atletas amadores.

\section{Método}

De janeiro de 2000 a fevereiro de 2009, foram descritas as lesões nos atletas masculinos de boxe amador durante os campeonatos préolímpicos, pan-americanos, brasileiros, jogos abertos do interior do Estado de São Paulo, paulistas e seletivas nacionais. As competições foram realizadas pela Confederação Brasileira de Boxe, Federação Paulista de Boxe, Confederação Pan-americana de Boxe e Associação Internacional de Boxe.

Todos os pugilistas realizaram um exame médico antes e após as lutas. $\mathrm{O}$ atendimento médico protocolado ao atleta ocorreu ou durante ou ao fim do combate. A ação do médico foi realizada conforme solicitação do árbitro, do próprio médico ou do atleta, nos casos de nocaute (concussão cerebral), sangramento nasal, lesão musculoesquelética, ferimento cortocontuso ou hematoma palpebral.

A maioria dos diagnósticos foi realizada clinicamente e, quando necessário, por meio de exame de imagem posteriormente à luta.

Esta pesquisa foi aprovada pelo Comitê de Ética da Faculdade de Medicina do ABC (FMABC), sob o parecer 337/2009.

\section{Resultados}

Foram realizados 2.892 atendimentos. A idade dos atletas variou de 17 a 34 anos, sendo todos do sexo masculino.

A equipe médica atuou em 1.446 lutas, com 291 lesões, como nocautes, sangramentos nasais, lesões musculoesqueléticas, ferimentos cortocontusos e hematoma palpebral (Tabela I). Das lesões musculoesqueléticas, as principais foram lesões ligamentares e fraturas nas mãos e punhos e luxações glenoumerais (Tabela II). Os ferimentos cortocontusos ocorreram principalmente na região supraorbital, intrabucal e palpebral (Tabela III). 
A topografia das lesões mais observada foi na face, correspondendo a $20,8 \%$ das lesões (Figura 1). Em seguida, registramos as lesões nas mãos e punhos, com $18,7 \%$, ombros, com $4 \%$ e joelhos, com $2 \%$ (Figura 2).

As lesões que levaram à interrupção das lutas, além dos 142 nocautes, foram 27 sangramentos nasais, 12 ferimentos supraorbitais, 6 luxações glenoumerais e 4 fraturas nasais.

\section{Discussão}

Em 1954, Blonstein e Clarke³ relataram que a principal lesão no boxe amador era a hemorragia nasal, seguida pelos ferimentos supraorbitais, luxação metacarpofalangeana do polegar, fraturas metacarpais e fratura dos ossos nasais. Nessa época não eram utilizados capacetes e as luvas tinham os polegares livres ${ }^{6}$.

No estudo de Timm et al. ${ }^{2}$, no qual avaliaram-se 1.219 lesões nos atletas da equipe amadora de boxe norte-americana, de 1977 a 1992 , $18 \%$ ocorreu na face, $15,3 \%$ nas mãos e punhos, $4,8 \%$ nos ombros e $4,4 \%$ nos joelhos. Em nosso estudo, foram $9,5 \%$ nas mãos, $8,6 \%$ na face, $2 \%$ nos ombros, $1,4 \%$ no nariz e $1 \%$ nos joelhos.

Zazryn et al realizaram um estudo com atletas do boxe profissional, de 1997 a 2005, e relataram 214 lesões em 907 lutas. Quando foram inclusos os nocautes como lesões, esse número aumentou para $60,7 \%$. A maioria das lesões foram ferimentos abertos na cabeça $(61,7 \%)$, seguidas de concussões $(11,7 \%)$ e fraturas das mãos e dedos $(4,7 \%)$. Ao contrário das lutas amadoras, nas lutas profissionais não é permitido ao médico terminar ou interromper a luta para examinar o atleta. Nessa situação, cabe ao árbitro permitir tal intervenção, podendo, posteriormente, seguir ou não as recomendações médicas.

Os atletas de boxe amador apresentam menor índice de lesões crônicas cerebrais, quando comparados aos atletas profissionais. Tal fato deve-se à menor exposição da cabeça aos repetitivos traumas, por lutas mais curtas e pelo uso obrigatório de protetores de cabeça ${ }^{8}$. No boxe amador é permitido ao médico interromper o combate quando um atleta é submetido a golpes excessivos, a fim de evitar lesões graves.

O conhecimento das regras e dos regulamentos do boxe é fundamental para que o médico à beira do ringue proteja a saúde do atleta com um exame clínico breve e limitado; o médico pode interromper a luta mesmo sem a solicitação do árbitro, o que é incomum e pouco frequente na prática esportiva em geral, obrigando que o mesmo mantenha atenção na luta durante todo o tempo.
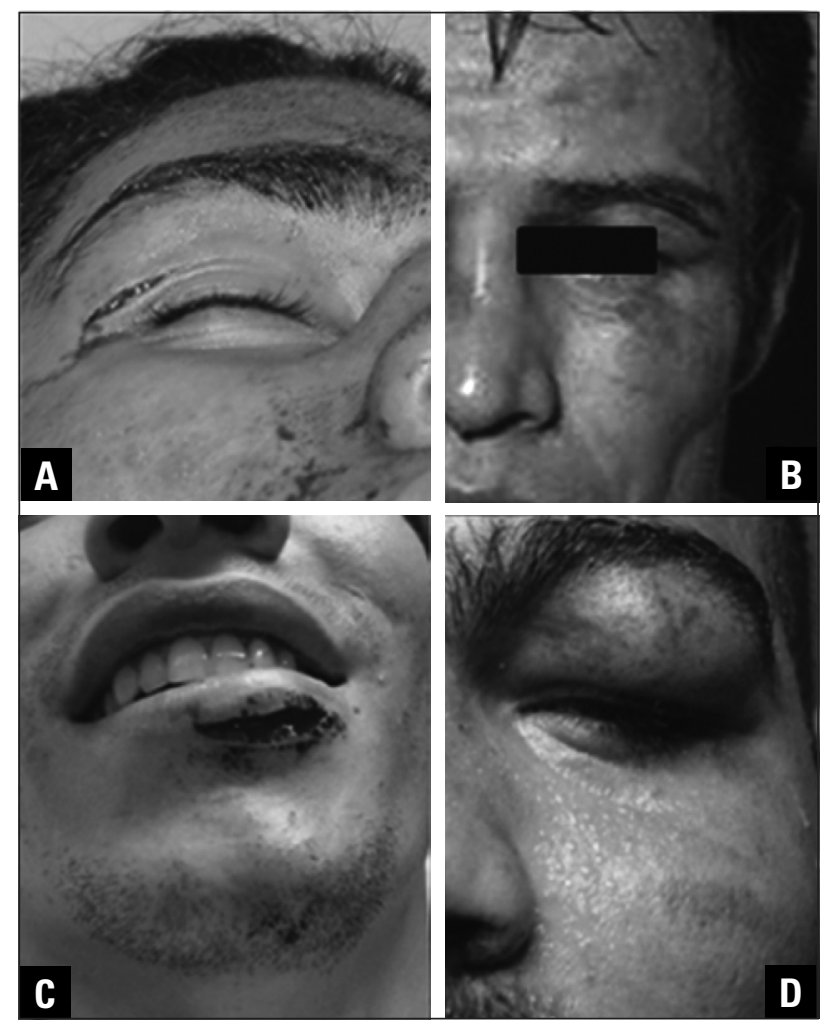

Figura 1 - Atletas do boxe amador apresentando ferimento cortocontuso supraorbital $(A)$, palpebral $(B)$, labial (C) e hematoma palpebral (D).
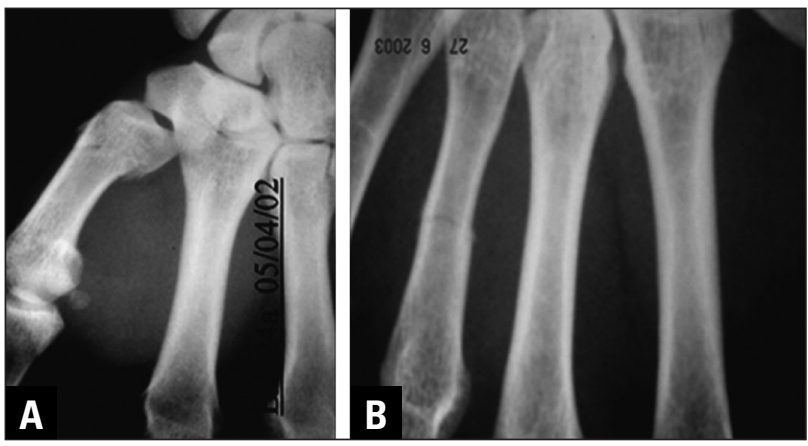

Figura 2 - Imagem radiográfica de atletas do boxe amador com fratura na base do primeiro metacarpo $(A)$ e na diáfise do quarto metacarpo (B).

As principais lesões no boxe amador durante as lutas foram, respectivamente, os nocautes, sangramentos nasais, lesões musculoesqueléticas e ferimentos cortocontusos. Os locais das lesões mais frequentes foram na face e nas mãos. 


\section{Referências}

1. Gambrell RC. Boxing: medical care in and out of the ring. Curr Sports Med Rep. 2007;6(5):317-21.

2. Timm KE, Wallach JM, Stone JA, Ryan EJ. Fifteen Years of Amateur Boxing Injuries/llnesses at the United States Olympic Training Center. J Athl Train. 1993;28(4):330-34.

3. Blonstein JL, Clarke E. The medical aspects of amateur boxing. Br Med J. 1954;2(4903):1523-5

4. Blonstein JL, Clarke E. Further observations on the medical aspects of amateur boxing. Br Med J. 1957;1 (5015):362-4.
5. Schmidt-Olsen S, Jensen SK, Mortensen V. Amateur boxing in Denmark. The effect of some preventive measures. Am J Sports Med.1990;18(1):98-100.

6. Jordan BD, Voy RO, Stone J. Amateur boxing injuries at the US Olympic Training Center. Phys Sportsmed. 1990;18(2):81-90.

7. Zazryn TR, McCrory PR, Cameron PA. Injury rates and risk factors in competitive professional boxing. Clin J Sport Med. 2009;19(1):20-5.

8. Clausen $\mathrm{H}, \mathrm{McC}$ rory $\mathrm{P}$, Anderson V. The risk of chronic traumatic brain injury in professional boxing: change in exposure variables over the past century. Br J Sports Med. 2005;39(9):661-4. 